\title{
Effect of sleeve gastrectomy on lipid parameters and cardiometabolic risk in young women
}

\section{Efeito da gastrectomia vertical nos parâmetros lipídicos e risco cardiometabólico em mulheres jovens}

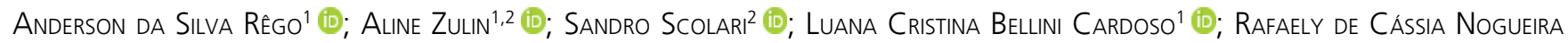
Sanches ${ }^{1}$; ; Maria Aparecida Salcl ${ }^{1}$ (i); Cremilde Aparecida Trindade Radovanovic ${ }^{1}$ (D).

\author{
A B S T R A C T
}

\begin{abstract}
Objective: to analyze the effect of vertical gastrectomy on lipid profile and cardiometabolic risk in young women, preoperatively and 6 months after the operation. Methods: retrospective study, encompassing medical record reviews of women's charts, preoperatively and in six months after the operation. Data collection was performed in the second half of 2015, using a review protocol with questions on the clinical-laboratory profile, anthropometric and laboratory classification of dyslipidemias. Descriptive and inferential analysis were used to treat the variables, using measures of variance, association and linear regression. Results: we analyzed medical records of 114 women undergoing vertical gastrectomy, with a mean age of $33.82 \pm 10.92$, and with complete high school education. There was a significant reduction of anthropometric data, as well as serum lipid values, six months after the surgical procedure. The coefficients of determination and the results of linear regression, showed that the reduction in serum triglyceride values and increase in high-density lipoprotein have a direct impact on the reduction of the cardiometabolic risk. Regarding the laboratory classification of dyslipidemias, it was observed that the majority presented a significant reduction at the six-month follow-up. Mixed hyperlipidemia showed no significant reduction. The categorized cardiometabolic risk showed a significant reduction in women at risk before vertical gastrectomy. Conclusion: at the six-month follow-up, vertical gastrectomy was effective in reducing the serum lipid profile and the cardiometabolic risk of young women when compared to the preoperative data. There was also a different improvement in the laboratory classification of dyslipidemias at the six-month follow-up after the surgical procedure.
\end{abstract}

Keywords: Obesity. Gastrectomy. Lipids. Cardiovascular Diseases. Bariatric Surgery.

\section{INTRODUCTION}

A Obesity is a global public health problem, with increasing prevalence in developed and developing countries. The World Health Organization (WHO) points out that more than 700 million people have morbid obesity, conditioned by eating habits, such as increased consumption of saturated fats and simple sugars, and decreased consumption of vegetables, grains and fruits. In addition, psychosocial factors, political, economic and cultural issues, associated with the inadequacy regarding food intake, favor body weight gain, being a condition that requires decentralized interventions for its reduction'.

In Brazil, data from the "Surveillance of Risk and Protective Factors for Chronic Diseases by Telephone

1 - Universidade Estadual de Maringá, Departamento de Enfermagem - Programa de pós-graduação em Enfermagem - Maringá - PR - Brasil

2 - Instituto de Cirurgia Bariátrica, Clínica privada de Gastroenterologia e Endocrinologia - Maringá - PR - Brasil 
Survey" (VIGITEL), carried out in 2018, showed that the majority of respondents claimed to be overweight (55.7\%), with higher rates in the male population (57.8\%) than in the female (53.9\%). For women, weight gain correlated with age and with a lower level of education².

The obesity associated with abnormalities in lipids' metabolism, glucose, and blood pressure, increases the probability of risk for cardiovascular diseases such as cerebrovascular events and Acute Myocardial Infarction ${ }^{3-4}$. Reduction of excess weight, dietary restriction of sugars and fat, as well as the practice of regular physical activity, are essential to reduce the risks of comorbidities. However, being obese entangles much complexity. A methanalysis encompassing six interventional studies did not indicate food and energy restriction as effective in weight loss 5 .

Primary interventions worldwide are still incipient when it comes to effective policies to reduce obesity, control biochemical and metabolic profiles, and provide remission of associated morbidities, such as arterial hypertension, diabetes Mellitus, hepatic steatosis, dyslipidemia, and metabolic syndrome ${ }^{3-4,6}$. In Brazil, the interventions are still held in the epidemiological context, with actions and measures on diet that are incipient in face of the severity of complications arising from the condition. In this scenario, the measures have not solved the growing incidence of obesity, with programmatic actions for educational interventions in the nutrition and food scope, and strategies focused on physical exercise, which are relevant to weight loss, but in the long term ${ }^{7}$.

The Basic Care Guidelines, mainly dealing with chronic diseases, show concern of the Ministry of Health $(\mathrm{MOH})$ with the growing demand for answers to questions regarding obesity's complications. The lack of effectiveness, intrinsic to the activities offered by the Unified Health System (SUS), carried out by professionals of the Family Health Strategy (FHS), has fragmented and weakened the care provided to people with obesity. Faced with this question, the individualized care, focusing on weight loss, has led people to seek more incisive interventions and results in the short term, such as bariatric surgery ${ }^{7-8}$.

Bariatric surgery is a therapeutic method for significant weight loss in a short period, resuming normal metabolic rates and reducing and/or correcting chronic diseases associated with obesity. The indication of the procedure follows a rigorous inter professional process, according to the patient's state of health and medical and professional recommendations. The indication to perform the surgical procedure is based on the prognosis in view of the health problems that can be reversed with the sleeve gastrectomy ${ }^{8-9}$.

The metabolic parameters altered with the surgical procedure need to be carefully evaluated by the health team professionals to control the reference levels. Cardiometabolic events must be monitored after sleeve gastrectomy to verify the reduction in the inflammatory and atherogenic impacts, worsened by primary dyslipidemias $^{10}$.

Studies have shown that sleeve gastrectomy has influence in the reduction of low density lipoproteins $(\mathrm{LDL}-\mathrm{C})$, total cholesterol (TC ), triglycerides (TG), and in the increase in high density lipoprotein $(\mathrm{HDL}-\mathrm{C})^{11-13}$. These results also show clinical improvement in chronic diseases, such as arterial hypertension and Diabetes Mellitus. A methanalysis ${ }^{14}$ was conclusive about the influence of bariatric surgery in the improvement of the metabolic profile. However, it reinforced the need for further studies to identify the clinical characteristics of obese people, and highlighted that the improvements resulting from surgical procedures for reduction and remission of chronic diseases are extremely important in the current scenario, where obesity is highly prevalent ${ }^{15}$.

Considering adipose dysfunction, which can lead to an increase in oxidative stress markers and to insulin resistance, especially with low HDL-c values, which reduces the anti-inflammatory, antithrombotic and antioxidant activity in the body, the question is: what is the impact of sleeve gastrectomy in the lipid profile, phenotype classification and cardiometabolic risk in young women with obesity, before and after the surgical procedure? Thus, the aim of this study was to analyze the effects of sleeve gastrectomy on the lipid profile and cardiometabolic risk of these women.

\section{METHODS}

\section{Design, study location and period}

This is a retrospective study, carried out in a clinical institution specialized in bariatric surgery. The 
institute is located in the city of Maringa, Parana state, Brazil, and performs an average of 10 operations a month. The institution's care protocol provides consultations in the preoperative and follow-up periods according to the patient's clinical need, with care by an interdisciplinary team, comprised of a gastroenterologist, an endocrinologist, a nurse, a psychologist, and a nutritionist.

After authorization, we collected data from clinical records at the research institution in the second half of 2015. Two nurses carried out the process, one master's degree and one PhD graduate at the Post-Graduate Program in Nursing, University of Maringa - UEM. The two participants received prior training for data collection and correct completion of the research instrument used.

\section{Population and sample}

The target population for this study was women with obesity who underwent sleeve gastrectomy in the period prior to data collection, with the convenience sample, according to the inclusion and exclusion criteria. The inclusion criteria were the existence of appropriate records of clinical, anthropometric, biochemical, and metabolic data, and pharmacological profile of the population.

We excluded medical records that did not contain data from consultations performed in the preoperative period or at six months after the operation. The decision to evaluate the clinical records in this period is based on the patients' lack of attendance in consultations beyond six months after surgery, which would reduce the sample. We excluded the male population due to the reduced rate of such individuals in the clinic, which predominantly attends the female population, but also in line with the theoretical aspects that supported the statistical analysis of this study.

\section{Study protocol}

For data collection, we used an instrument developed by the authors, based on a literature review on the variables used to assess the effectiveness of sleeve gastrectomy. We collected data on all variables for the preoperative and the six-month follow-up periods. The instrument contained the following variables:
- Sociodemographic characteristics: age and education;

- Anthropometric measurements: weight, height, body mass index (BMI), waist circumference, obesity degree;

- Presence of comorbidities: systemic arterial hypertension (SAH), Diabetes Mellitus (DM), metabolic syndrome (MS), dyslipidemia and its classifications, hepatic steatosis and heart disease;

- Biochemical and metabolic parameters: fasting blood glucose, red blood cells, total proteins, albumin, serum iron, ferritin, vitamin B12, low density lipoproteins $(\mathrm{LDL}-\mathrm{C})$, high density lipoprotein (HDL-C), total cholesterol (TC), triglycerides (TG), transaminases (TGO-AST, TGP-ALT), alkaline phosphatase, and gamma glutamyl transferase (GGT);

- Pharmacological profile.

For the laboratory classification of dyslipidemias, we followed the guidelines of the Brazilian Society of Endocrinology and Metabolism ${ }^{16}$, which considers hypercholesterolemia the isolated elevation of LDL c $(\geq$ $160 \mathrm{mg} / \mathrm{dL}$ ); hypertriglyceridemia, the isolated elevation of TG ( $\geq 150 \mathrm{mg} / \mathrm{dL})$; mixed hyperlipidemia, values of LDL c ( $\geq 160 \mathrm{mg} / \mathrm{dL})$ and TG ( $\geq 150 \mathrm{mg} / \mathrm{dL})$ above the values of reference; and dyslipidemia, the reduction in HDL c levels and an increase in total cholesterol and triglyceride values in plasma. We used the TG/HDL c ratio to assess cardiometabolic risk, considering high risk when this relationship resulted in a value $\geq 3.8^{17}$.

\section{Analysis of results and statistics}

We checked the data to identify and correct possible flaws and doubly transcribed them to a Microsoft Excel 2016 spreadsheet. We treated the variables with the aid of the Statistical Package for the Social Sciences (SPSS) software, version 20.0. We verified data normality with the Kolmogorov-Smirnov test, with Lilliefors correction.

We used the paired t-test to verify whether there was significance between the values referring to the variables of the lipid and anthropometric profiles, such as weight, BMI and WC. We should note that, as the 
objective of the study included the lipid profile and cardiometabolic risk, we described the anthropometric values, but did not include them in the tables. We used the chi square test to verify whether there was a significant difference in the laboratory classification of dyslipidemia. We considered a significance level of $p<0.05$ for all tests performed.

To assess the correlation between the cardiometabolic risk and the variables related to the lipid profile, we used a scatter diagram, assuming the hypothetical model $y=f(x)$, in which y represents the continuous values of the cardiometabolic risk, and $x$, the continuous values of LDL c, HDL c, total cholesterol, and triglycerides, in both preoperative and six month followup periods of sleeve gastrectomy.

After the calculation, we performed a linear regression analysis from the equation $y=b x+a$ to fit the trend line to the dispersion diagram, to establish the determination coefficient $\left(R^{2}\right)$, and to verify the variability of the data resulting from this analysis. We assessed variables independence using the Durbin-Watson test, in which there was no autocorrelation $(1.98, p<0.001)$.

\section{Ethical aspects}

This study is part of a larger research entitled "Pre and postoperative characterization of clinical conditions of obese people in bariatric surgery." The project of which this research is part complied with the resolution 466/2012 ${ }^{18}$, being approved by the Standing Committee on Ethics in Research with Human Beings under opinion number 1,246,542/2015. To guarantee confidentiality, we followed the recommendation of the Ethics Committee to collect data from the sociodemographic characteristics limited only to age and education, due to the request for waiver of the Informed Consent Form (ICF).

\section{RESULTS}

We analyzed medical records of 114 women who underwent sleeve gastrectomy, with a mean age of $33.82 \pm 10.92$ and complete high school. There was a reduction in anthropometric parameters, in which the weight in the preoperative period and six months of follow-up was $106.84 \pm 15.56 \mathrm{~kg}$ and $76.21 \pm 14.25$ $\mathrm{kg}$, respectively. The BMI, on its turn, varied from 40.03 $\pm 3.80 \mathrm{~kg} / \mathrm{m}^{2}$ to $28.55 \pm 4.07 \mathrm{~kg} / \mathrm{m}^{2}$, considering the two periods. Table 1 shows changes in metabolic parameters, with significance for LDL cholesterol $(p=$ $0.015)$, TC $(p=0.008)$, TG $(p=0.001)$, and a reduction in the cardiometabolic risk $(p=0.001)$. There was a significant increase of HDL c (0.001).

Table 1. Clinical characteristics of women in the preoperative period and six months after sleeve gastrectomy.

\begin{tabular}{lccc}
\hline & Preoperative & Postoperative & \multirow{2}{*}{$\mathrm{p}$} \\
\cline { 2 - 3 } & $\mathrm{M} \pm \mathrm{DP}$ & $\mathrm{M} \pm \mathrm{DP}$ & \\
\hline $\mathrm{HDL}-\mathrm{c} \mathrm{mg} / \mathrm{dL}$ & $51.10 \pm 14.74$ & $57.10 \pm 14.17$ & 0.001 \\
$\mathrm{LDL}-\mathrm{c} \mathrm{mg} / \mathrm{dL}$ & $114.09 \pm 32.55$ & $107.37 \pm 32.67$ & 0.015 \\
$\mathrm{CT} \mathrm{mg/dL}$ & $195.21 \pm 36.11$ & $186.54 \pm 32.86$ & 0.008 \\
$\mathrm{TG} \mathrm{mg} / \mathrm{dL}$ & $151.30 \pm 69.52$ & $110.04 \pm 49.91$ & 0.001 \\
TG/HDL-c & $3.25 \pm 1.85$ & $2.03 \pm 1.06$ & 0.001 \\
\hline
\end{tabular}

Legend: LDL-c: low-density lipoproteins; HDL-c: high-density lipoprotein; TC: Total Cholesterol; TG: Triglycerides; mg/dL: milligrams per deciliter.

Figure 1 shows the data dispersion, the trend line and the $R^{2}$ in the preoperative period of sleeve gastrectomy. The LDL $c$ and TC lipid parameters displayed a steep line and low $R^{2}(0.026$ and 0.0369 , respectively), showing that these parameters do not influence the cardiometabolic risk. HDL $c$ and $\mathrm{TG}$, being lipid parameters used in the calculation of cardiometabolic risk, both explained $32 \%\left(R^{2}=0.3263\right)$ of the variation of said parameter values, wherein the lower HDL $c$, the greater the risk $\left(R^{2}=0.3263\right)$. The same is explained by the TG, which predicted $72 \%\left(R^{2}\right.$ $=0.7225$ ) of the cardiometabolic risk values.

The LDL-C and TC values still do not explain the variation in cardiometabolic risk in the six-month followup period. With the surgical procedure, there was an increase in $\mathrm{HDL}$ c values, which reduced the coefficient of determination $\left(R^{2}=0.1852\right)$. The reduction in the coefficient of determination also followed a reduction in the TG values after sleeve gastrectomy, however, it has a self-explanatory power in the variation of the cardiometabolic risk $\left(R^{2}=0.7231\right)$. In summary, the reduction in triglycerides and the increase in $\mathrm{HDL} c$ reduce the cardiometabolic risk of women undergoing sleeve gastrectomy (Figure 2). 

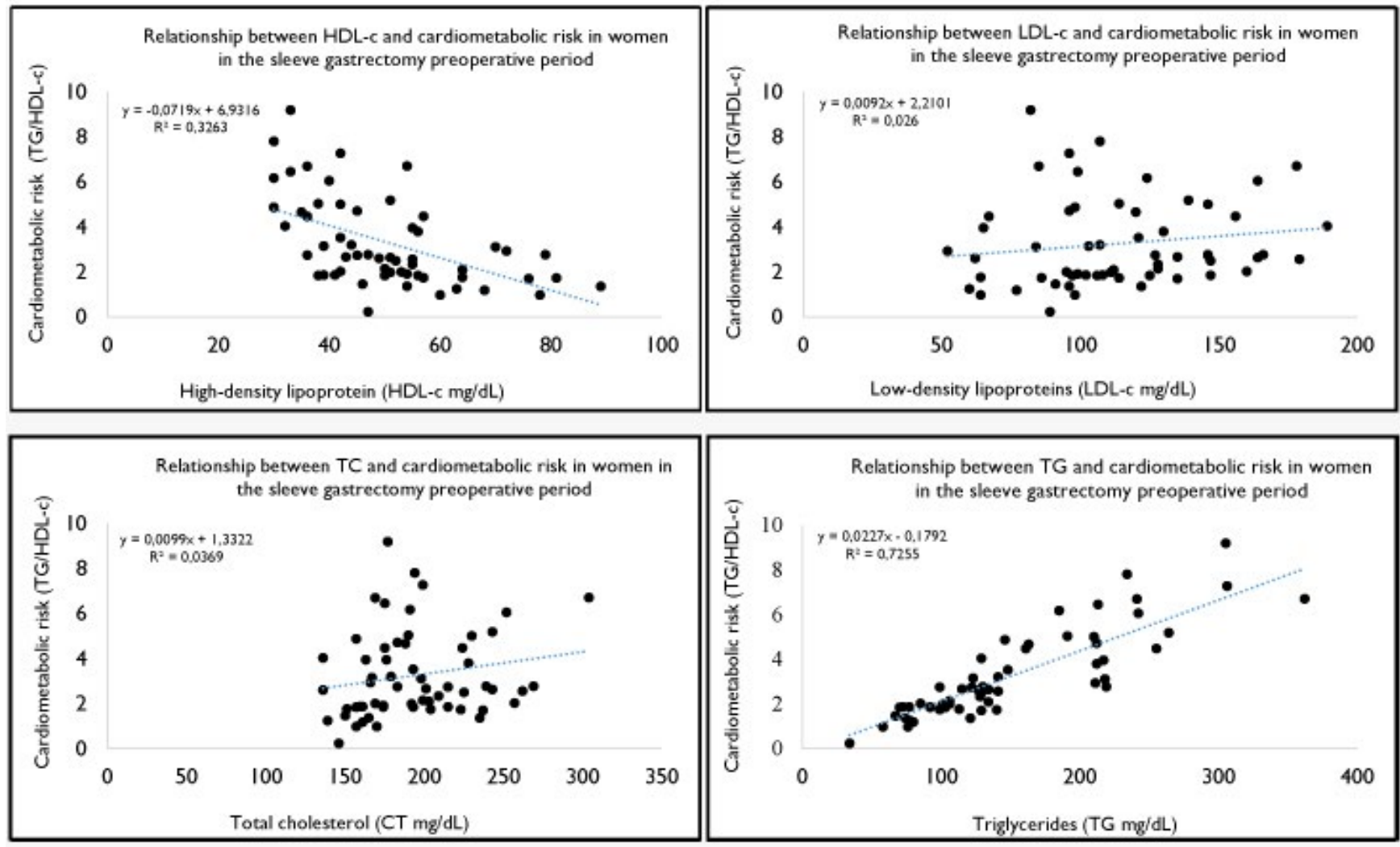

Figure 1. Relationship between lipid parameters and cardiometabolic risk in the sleeve gastrectomy preoperative period. Legend: LDL-c: low-density lipoproteins; HDL-c: high-density lipoprotein; TC: Total Cholesterol; TG: Triglycerides; mg/dL: milligrams per deciliter.
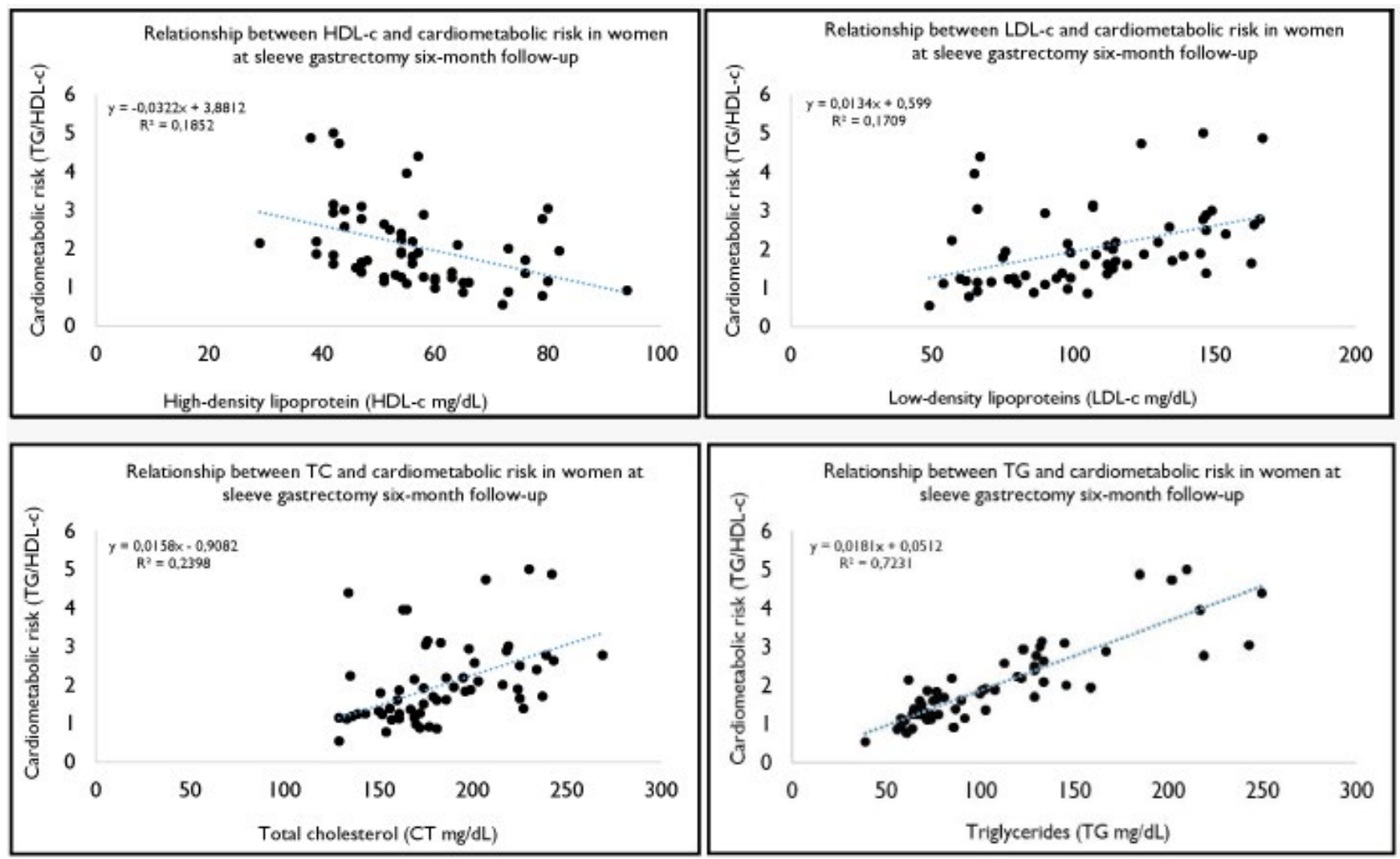

Figure 2. Relationship between lipid parameters and cardiometabolic risk at sleeve gastrectomy six-month follow-up.

Legend: LDL-c: low-density lipoproteins; HDL-c: high-density lipoprotein; TC: Total Cholesterol; TG: Triglycerides; mg/dL: milligrams per deciliter. 
As for the laboratory classification of the procedure. There was no significant reduction in dyslipidemia, we observed that most patients mixed hyperlipidemia $(p=0.127)$. The cardiometabolic presented a significant reduction at six-month risk decreased significantly after sleeve gastrectomy ( $p$ follow-up when compared with the period before $=0.001$ ) (Table 2).

Table 2. Laboratory classification of dyslipidemias in the preoperative period and six months after sleeve gastrectomy.

\begin{tabular}{|c|c|c|c|c|c|}
\hline & \multicolumn{2}{|c|}{ Preoperative } & \multicolumn{2}{|c|}{ Postoperative } & \multirow{2}{*}{$p$} \\
\hline & $\mathrm{N}$ & $\%$ & $\mathrm{~N}$ & $\%$ & \\
\hline \multicolumn{6}{|c|}{$\begin{array}{l}\text { Isolated hypercholesterolemia: isolated elevation of } \\
\mathrm{LDL}-\mathrm{c}(\geq 160 \mathrm{mg} / \mathrm{dL})\end{array}$} \\
\hline Yes & 13 & 11.4 & 9 & 7.9 & $<0.001$ \\
\hline No & 101 & 88.6 & 105 & 92.1 & \\
\hline \multicolumn{6}{|c|}{$\begin{array}{l}\text { Isolated hypertriglyceridemia: isolated elevation of TG } \\
\text { ( } \geq 150 \mathrm{mg} / \mathrm{dL})\end{array}$} \\
\hline Yes & 40 & 35.1 & 20 & 17.5 & $<0.001$ \\
\hline No & 74 & 64.9 & 94 & 82.5 & \\
\hline \multicolumn{6}{|c|}{$\begin{array}{l}\text { Mixed hyperlipidemia: increased values of LDL-c ( } \geq \\
160 \mathrm{mg} / \mathrm{dL} \text { ) and TG ( } \geq 150 \mathrm{mg} / \mathrm{dL} \text { ) }\end{array}$} \\
\hline Yes & 5 & 4.4 & 3 & 2.6 & 0.127 \\
\hline No & 109 & 98.6 & 111 & 97.4 & \\
\hline \multicolumn{6}{|l|}{ Low HDL } \\
\hline Yes & 54 & 47.4 & 39 & 34.2 & $<0.001$ \\
\hline No & 60 & 52.6 & 75 & 65.8 & \\
\hline \multicolumn{6}{|l|}{ Dyslipidemia } \\
\hline Yes & 39 & 34.2 & 4 & 3.5 & 0.012 \\
\hline No & 75 & 35.8 & 110 & 96.5 & \\
\hline \multicolumn{6}{|c|}{ Cardiometabolic risk } \\
\hline TG / HDL-c <3.8 & 78 & 68.4 & 103 & 90.4 & $<0.001$ \\
\hline TG / HDL-c $\geq 3.8$ & 36 & 31.6 & 11 & 9.6 & \\
\hline
\end{tabular}

Legend: LDL-c: Low-density lipoproteins; HDL-c: High-density lipoprotein; TC: Total Cholesterol; TG: Triglycerides;

$\mathrm{mg} / \mathrm{dL}$ : milligrams per deciliter.

\section{DISCUSSION}

The remission of obesity-induced dyslipidemia has a direct, negative impact on the cardiometabolic risk. Studies ${ }^{4,15,19-20}$ have demonstrated the effectiveness of sleeve gastrectomy on resuming reference levels, in accordance with entities of Endocrinology and Metabolism. A meta-analysis showed reduction of serum lipid levels after bariatric procedures, though varying widely, likely due to anatomical alterations inherent to each surgical technique. These differences may be relevant in deciding the most appropriate technique for a given patient ${ }^{21}$.

Sociodemographic parameters, specifically those of the age group, are relevant in reducing serum lipid levels after surgery. Adult patients, between 18 and 59 years of age, are more prone to weight loss and reduction of serum lipid levels due to the improved carbohydrates metabolism and the hormonal effect in the gastrointestinal system, particularly by sleeve gastrectomy ${ }^{3}$.

Weight loss has also been reported by a metaanalysis ${ }^{21}$ and national and international researches 3 3, 15,20. Surgical techniques have a fundamental role in the 
considerable improvement of the anthropometric and metabolic parameters, which is reinforced by data related to clinical factors, such as the presence of morbidities and lifestyle, eating and smoking habits. In addition, drug therapy with statins and fibrates have correlation with weight loss and reduction of BMI and visceral fat ${ }^{3,15,20}$.

There has been evidence that weight loss is associated with important reduction in biochemical and metabolic parameters, such as the lipid profile, in the short term ${ }^{21}$. However, there is a need of better explanations on the weight loss and the reduction of $\mathrm{BMI}$ and visceral fat, which is key to lipid values. These elements are intrinsic to the cardiometabolic risk due to heterogeneous profile ${ }^{22}$.

The increase in serum HDL $c$ is explained by weight loss, but also by the reduction of visceral fat and of insulin resistance. The organism is able to metabolize excess fat and to reduce markers of oxidative stress, mediated by the anti inflammatory, anti thrombotic and antioxidant activity of the lipoprotein ${ }^{23}$. A randomized clinical trial performed with 40 women undergoing sleeve gastrectomy showed the variation of lipid values in six months and one year after the procedure ${ }^{24}$.

The significant increase in $\mathrm{HDL} \mathrm{c}$ also reduces the risk of atherogenesis, which is the oxidation of LDL cholesterol in the artery walls. There is cholesterol remission in peripheral tissue, transporting it to the liver and excreting it through the bile and feces. Thus, the increase in $\mathrm{HDL} c$ is attributed to the reduction of small and dense particles to large and fluctuating LDL-C particles, which tend to decrease cholesterol and bile salts reabsorption by the intestine $\mathrm{e}^{22,24}$.

Importantly, sleeve gastrectomy can raise HDL c levels, but concomitant to this increase are the changes in feeding habits, marked by decreased quantity and improved quality, according to the clinical and nutritional follow-up. The regular practice of physical exercises can be a strategy to reduce cardiovascular events and improve the quality of life of this population. These strategies can be adopted, especially for overweight individuals who do not have indication of surgical procedures, such as grade I obesity patients ${ }^{24}$.

LDL-c had a reduction after surgical procedures. Nonetheless, there is need to delineate the variation of LDL c particles, which can present significant oxidative markers, resulting from the reduction of such lipoprotein. These subfractions can display an atherogenic profile, wherein reduced-size LDL c particles have a greater effect on tissue inflammation and oxidation, which should be measured by C-reactive protein (CRP) ${ }^{25}$.

TC decreased significantly and these data reinforce the results from a meta-analysis ${ }^{26}$ on the impact of bariatric surgery on lipids metabolism. These decreased after the procedure, and only changes in surgical techniques interfered in TC serum values ${ }^{26}$. Said meta-analysis also included TG, which are formed by carbohydrates stored in the cells for calorie reserve, and used when the body needs energy after food restriction. This restriction is a direct factor in changing the TG parameters in relation to reference values, acting in the reduction of the inflammatory cytokines present in obese individuals ${ }^{11}$.

Regarding cardiometabolic risk, studies ${ }^{27,28}$ show that sleeve gastrectomy is effective in weight loss and improves serum lipid levels, reducing cardiometabolic risk factors inherent to the complications of obesity, especially in the first year after the procedure. A metaanalysis reported that the bariatric procedure has a favorable effect on $\mathrm{TG} / \mathrm{HDL}$ c, pointing to slower coronary atherosclerosis, especially in patients who had diabetes Mellitus as the underlying disease ${ }^{26}$.

The cardiometabolic risk, calculated from the ratio established by Hanak et al. ${ }^{17}$ used only serum TG and HDL c values ${ }^{29-31}$. Thus, the present research is limited to the calculation of cardiometabolic risk by exploring the values and parameters of the lipid profile before and after bariatric surgery. Assessments that are more accurate are required, such as the carotid intima-media thickness marker, worsened by atherosclerosis, evidenced by laboratory and imaging tests, such as ultrasound and ultra resolution echo-color Doppler, which are costly procedures ${ }^{32-34}$. Moreover, another important limitation is related to the target population of young women, and in a private practice from only one municipality, which reduces the power of generalization of the study.

It is worth mentioning that the surgical technique, such as sleeve gastrectomy, impacts results according to different moments and the patient's clinical condition, but there is efficiency in improving the endocrine and metabolic states. It is up to the health 
professional to thoroughly examine the patient's situation, the associated morbidity and the socio-demographic factors that might interfere with postoperative recovery and with the direct response to bariatric surgery ${ }^{28}$.

As for the study's contributions, stands out the simple equation developed by Hanak et al. ${ }^{17}$ and the potential to predict the severity of cardiometabolic risk markers. From this, following clinical protocols for more accurate diagnosis of the examined risk factors leads to cost savings for the institutions that perform sleeve gastrectomy, or any other bariatric surgery, especially for institutions that serve the public health system and health insurance companies. The cardiometabolic risk described from this equation is not only inherent to bariatric surgery, and can be performed by many health professionals to identify risk factors related to cardiovascular events, worsened by changes in lipid parameters ${ }^{29-31}$.

The present study is limited by the reverse causality bias, which is inherent to studies with this methodological approach, and may have altered some associations' results. Furthermore, the study only addresses the profile of the female population, which increases the limitation and hinders the power of generalization. There is need to conduct and disseminate results related to experiences during the period of 12 months or more after the operation. These could then show the interactions between intrapersonal, behavioral and environmental influences for a better understanding of patients' experiences as to the maintenance of weight loss after bariatric surgery ${ }^{28,29}$.

We conclude that sleeve gastrectomy was effective in reducing serum values of lipids such as LDL c, TC and TG, and in increasing HDL-C and potentially reducing the cardiometabolic risk, in the six months following the procedure. Moreover, we emphasize that additional tests to ascertain the cardiometabolic risk, as well as appropriate monitoring of patients undergoing surgery, may provide more accurate diagnosis, and assist in the development and introduction of effective, clinically-individualized interventions.

\title{
R E S U M O
}

\begin{abstract}
Objetivo: analisar o efeito da gastrectomia vertical no perfil lipídico e risco cardiometabólico em mulheres jovens, no pré-operatório e com seis meses de seguimento. Métodos: estudo retrospectivo, realizado a partir de consultas a prontuários de mulheres, no préoperatório e com seis meses de seguimento. A coleta de dados foi realizada no segundo semestre de 2015, utilizando-se roteiro com questões sobre o perfil clínico-laboratorial, antropométrico e da classificação laboratorial da6s dislipidemias. Para tratamento das variáveis, foi utilizada análise descritiva e inferencial, por meio de medidas de variância, associação e regressão linear. Resultados:

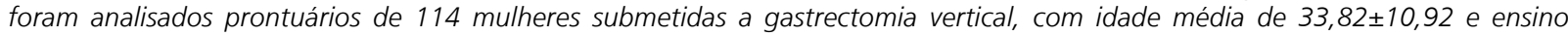
médio completo. Houve redução significativa da antropometria, como também dos valores séricos dos lipídios após seis meses de seguimento do procedimento cirúrgico. Os coeficientes de determinação, resultados da regressão linear, mostraram que a redução dos valores séricos dos triglicerídeos e o aumento da lipoproteína de alta densidade têm explicação direta na redução do risco cardiometabólico. Quanto à classificação laboratorial das dislipidemias, observou-se que a maioria apresentou redução significativa, no seguimento de seis meses. A hiperlipidemia mista não teve redução significativa. O risco cardiometabólico, categorizado, teve redução significativa em mulheres que apresentavam risco antes da gastrectomia vertical. Conclusão: no seguimento de seis meses, houve eficácia da gastrectomia vertical na redução dos valores séricos do perfil lipídico e do risco cardiometabólico de mulheres jovens, em relação ao período pré-operatório. A classificação laboratorial das dislipidemias também teve redução dos parâmetros, no seguimento de seis meses após o procedimento cirúrgico.
\end{abstract}

Palavras chave: Obesidade. Gastrectomia. Lipídeos. Doenças Cardiovasculares. Cirurgia Bariátrica.

\section{REFERENCES}

1. World Health Organization. Obesity: preventing and managing the global epidemic. Geneva: World Health Organization; 2000.

2. Ministério da Saúde (BR). Secretaria de Vigilância em Saúde. Departamento de Análise em Saúde e Vigilância de Doenças não Transmissíveis. Vigitel Brasil 2018: vigilância de fatores de risco e proteção para doenças crônicas por inquérito telefônico: estimativas sobre frequência e distribuição sociodemográfica de fatores de risco e proteção para doenças crônicas nas capitais dos 26 estados brasileiros e no Distrito Federal em 2018. Brasília (DF): Ministério da Saúde; 2019.

3. Cunha FM, Oliveira J, Preto J, Saavedra A, Costa MM, Magalhães $D$, et al. The Effect of Bariatric Surgery Type on Lipid Profile: An Age, Sex, Body Mass Index and Excess Weight Loss Matched Study. Obes Surg. 2016;26(5):1041-7.

4. Carbajo MA, Fong-Hirales A, Luque-de-León E, 
Molina-Lopez JF, Ortiz-de-Solórzano J. Weight loss and improvement of lipid profiles in morbidly obese patients after laparoscopic one-anastomosis gastric bypass: 2-year follow-up. Surg Endosc. 2017;31(1):416-21.

5. Harris L, Hamilton S, Azevedo LB, Olajide J, De Brún C, Waller $G$, et al. Intermittent fasting interventions for treatment of overweight and obesity in adults: a systematic review and meta-analysis. JBI Database Syst Rev Implement Rep. 2018;16(2):507-47.

6. Zomer E, Gurusamy K, Leach R, Trimmer C, Lobstein $T$, Morris $S$, et al. Interventions that cause weight loss and the impact on cardiovascular risk factors: a systematic review and meta-analysis. Obes Rev. 2016;17(10):1001-11.

7. Dias PC, Henriques $P$, Anjos LA dos, Burlandy L. Obesity and public policies: the Brazilian government's definitions and strategies. Cad. Saúde Pública. 2017;33(7): e00006016.

8. Rêgo AS, Zulin A, Scolari S, Marcon SS, Radovanovic CAT. Análise das condições médicas de pacientes obesos nos períodos pré e pós-operatório de cirurgia bariátrica. Rev Col Bras Cir 2017;44(2):171-8.

9. Marques LR, Diniz TA, Antunes BM, Rossi FE, Caperuto EC, Lira FS, et al. Reverse Cholesterol Transport: Molecular Mechanisms and the Nonmedical Approach to Enhance HDL Cholesterol. Front Physiol. 2018;9:526.

10. Tedesco AK, Biazotto R, Gebara TSS, Cambi MPC, Baretta GAP. Pre- and postoperative in bariatric surgery: some biochemical changes. ABCD Arq Bras Cir Dig. 2016;29(Suppl 1):67-71.

11. Lira NS, Macedo CES, Belo GM, Santa-Cruz F, Siqueira LT, Ferraz ÁAB. Análise do perfil lipídico de pacientes submetidos à gastrectomia vertical e à derivação gástrica em Y de Roux. Rev Col Bras Cir. 2018;45(6):e1967.

12. Santos TD dos, Burgos MGP de A, Lemos M da CC de, Cabral PC. Clinical and nutritional aspects in obese women during the first year after roux-en-y gastric bypass. ABCD Arq Bras Cir Dig. 2015;28(Suppl 1):56-60.

13. Climent E, Benaiges D, Flores-Le Roux JA, Ramón JM, Pedro-Botet J, Goday A. Changes in the lipid profile 5 years after bariatric surgery: laparoscopic Roux-en-Y gastric bypass versus laparoscopic sleeve gastrectomy. Surg Obes Relat Dis. 2018;14(8):1099-105.

14. Faludi A, Izar M, Saraiva J, Chacra A, Bianco H, Afiune Neto $A$, et al. Atualização da diretriz brasileira de dislipidemias e prevenção da aterosclerose - 2017. Arq Bras Cardiol. 2017;109(2 Supl 1):1-76.

15. Hanak V, Munoz J, Teague J, Stanley A, Bittner $V$. Accuracy of the triglyceride to high-density lipoprotein cholesterol ratio for prediction of the low-density lipoprotein phenotype B. Am J Cardiol. 2004;94(2):219-22.

16. Conselho Nacional de Saúde. Resolução número 466, de 12 de dezembro de 2012. Diário Oficial da União. 12 Dez 2012.

17. Min T, Prior SL, Churm R, Dunseath G, Barry JD, Stephens JW. Effect of Laparoscopic Sleeve Gastrectomy on Static and Dynamic Measures of Glucose Homeostasis and Incretin Hormone Response 4-Years Post-Operatively. Obes Surg. 2020;30(1):4655.

18. Voglino C, Tirone A, Ciuoli C, Benenati N, Paolini $B$, Croce $F$, et al. Cardiovascular Benefits and Lipid Profile Changes 5 Years After Bariatric Surgery: A Comparative Study Between Sleeve Gastrectomy and Roux-en-Y Gastric Bypass. J Gastrointest Surg. 2019 Dec 16. doi: 10.1007/s11605-019-04482-9.

19. Heffron SP, Parikh A, Volodarskiy A, Ren-Fielding C, Schwartzbard A, Nicholson J, et al. Changes in Lipid Profile of Obese Patients Following Contemporary Bariatric Surgery: A Meta-Analysis. Am J Med Sci. 2016;129(9):952-9.

20. Alqahtani A, Al-Darwish A, Mahmoud AE, Alqahtani YA, Elahmedi M. Short-term outcomes of endoscopic sleeve gastroplasty in 1000 consecutive patients. Gastrointest Endosc. 2019;89(6):1132-8.

21. Askarpour M, Khani D, Sheikhi A, Ghaedi E, Alizadeh S. Effect of Bariatric Surgery on Serum Inflammatory Factors of Obese Patients: a Systematic Review and Meta-Analysis. Obes Surg. 2019;29(8):2631-47.

22. Gómez-Martin JM, Balsa JA, Aracil E, Cuadrado-Ayuso $M$, Rosillo M, De la Peña $G$, et al. Beneficial changes on plasma apolipoproteins $A$ and $B$, high density lipoproteins and oxidized low density lipoproteins in obese women after bariatric surgery: comparison between gastric bypass and sleeve gastrectomy. 
Lipids Health Dis. 2018;17(1):145.

23. Coimbra S, Reis F, Ferreira C, Nunes $S$, Viana $S$, Catarino $A$, et al. Weight loss achieved by bariatric surgery modifies high-density lipoprotein subfractions and low-density lipoprotein oxidation towards atheroprotection. Clin Biochem. 2019;63:46-53.

24. Qi L, Guo Y, Liu C-Q, Huang Z-P, Sheng Y, Zou D-J. Effects of bariatric surgery on glycemic and lipid metabolism, surgical complication and quality of life in adolescents with obesity: a systematic review and meta-analysis. Surg Obes Relat Dis. 2017; 13(12):2037-55.

25. Zhao X, Duan W, Sun C, Li Z, Liu Y, Xiao X, et al. Decreased Cardiovascular Risk after Roux-en-Y Gastric Bypass Surgery in Chinese Diabetic Patients with Obesity. J Diabetes Res. 2017;2017: 5612049.

26. Gero D, Favre L, Allemann P, Fournier P, Demartines N, Suter M. Laparoscopic Roux-En-Y Gastric Bypass Improves Lipid Profile and Decreases Cardiovascular Risk: a 5-Year Longitudinal Cohort Study of 1048 Patients. Obes Surg. 2018;28(3):805-11.

27. Konieczna J, Abete I, Galmés AM, Babio N, Colom $A$, Zulet MA, et al. Body adiposity indicators and cardiometabolic risk: Cross-sectional analysis in

Received in: 25/03/2020

Accepted for publication: 01/06/2020

Conflict of interest: no.

Funding source: none. participants from the PREDIMED-Plus trial. Clin Nutr. 2019;38(4):1883-91.

28. Sultani $R$, Tong DC, Peverelle $M$, Lee YS, Baradi $A$, Wilson AM. Elevated Triglycerides to High-Density Lipoprotein Cholesterol (TG/HDL-C) Ratio Predicts Long-Term Mortality in High-Risk Patients. Heart Lung Circ. 2020;29(3):414-24.

29. Qin H, Chen Z, Zhang Y, Wang L, Ouyang P, Cheng $\mathrm{L}$, et al. Triglyceride to high-density lipoprotein cholesterol ratio is associated with incident diabetes in men: A retrospective study of Chinese individuals. J Diabetes Investig. 2020;11(1):192-8.

30. Leeman $M$, van Mil SR, Al-Ghanam I, Biter LU, Dunkelgrun M, Castro Cabezas M. Structural and functional vascular improvement 1 year after bariatric surgery: a prospective cohort study. Surg Obes Relat Dis. 2019;15(10):1773-9.

31. Liebl L, Barnason S, Brage Hudson D. Awakening: a qualitative study on maintaining weight loss after bariatric surgery. J Clin Nurs. 2016;25(7-8):951-61.

32. Felsenreich DM, Langer FB, Prager $G$. Weight loss and resolution of comorbidities after sleeve gastrectomy: a review of long-term results. Scand J Surg. 2019;108(1):3-9.

\section{Mailing address:}

Anderson da Silva Rêgo

E-mail: andersondsre@gmail.com

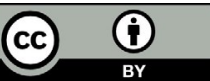

